\title{
Monte Carlo characterization of the gold nanoparticles dose enhancement and estimation of the physical interactions weight in dose enhancement mechanism
}

\author{
Mohammad MOHAMMADZADEH ${ }^{\mathrm{a}, \mathrm{b}}$, Hosein GHIASI, ${ }^{\mathrm{a}, \mathrm{b},}$ \\ ${ }^{a}$ Radiation Oncology Department, Shaid Madani Hospital. Tabriz, Iran \\ ${ }^{b}$ Medical Radiation Sciences Research Team, Imam Hospital, Tabriz University of Medical Sciences, Tabriz, Iran \\ *E-mail address: hoseinghiasi62@gmail.com
}

\begin{abstract}
Radiosensitization of the cancer cells by the heavy atoms of nanoparticles was the subject of some studies. But, the physical characterization to determine the weight of all interactions hasn't been made numerically. The aim of this study was to calculate and compare the dose enhancement (DE) for different energies. The Monte Carlo simulation method was used in the current study. The influence of gold nanoparticles (GNP) size, beam quality, the GNP concentration, and dose inhomogeneity on the radiosensitization by DE was studied. A 35\% increase in the photoelectric effect was observed while energy decreased from $18 \mathrm{MV}$ to $300 \mathrm{kV}$. In the microscopic study which DE calculated in $30 \mu \mathrm{m}$ from a single GNP, a 79\% decreasing in DE within the first $1 \mu \mathrm{m}$ was seen and it declined to $2 \%$ in $30 \mu \mathrm{m}$ from the GNP center. The effect was observed at small distances only. Our study revealed that the dose inhomogeneity around a nanoparticle is the main and very strong effect of DE on a macroscopic scale. In the location which $35 \%$ DE occurs most malignant cells survival will be effectively reduced. Our research indicates the need for further research.
\end{abstract}

Key words: gold nanoparticles; dose enhancement; Monte Carlo.

\section{Introduction}

The presence of the gold nanoparticles in the vicinity of the cancer cells has been shown to sensitize cancer cells. Besides the macroscopic dose enhancement (MDE), the detailed analysis of the influence of different interactions, namely the photoelectric effect, pair-production, Compton scattering, and others may be helpful to understand the mechanism of dose enhancement. It might help in choosing the proper energy and nanoparticle. In recent decades there have been extensive efforts to deliver the required dose to tumoral tissue with less harmful effects on the healthy organs. One of the approaches has employed nono-scaled material to achieve this goal. In the GNP aid radiotherapy method (GNRT), cellular scaled gold particles are used to create a favorable contrast in absorbed dose between the tumor and surrounding healthy organs. Different researches have worked on the characteristics of GNPs as a contrast agent for radiation therapy. Theoretical and experimental studies have reported that the presence of GNPs in tumor cells can cause higher dose absorption inside the cells. ${ }^{1}$ In other words, the presence of GNPs in the tumor enhances the deleterious effects of radiation on the tumor cells. Recent developments in cancer research have revealed an enhancement in the tumor cell killing in the GNRT. ${ }^{2-4}$ A new study also reported its application with proton beam radiotherapy. Using a cancer cell line in vitro, Jeynes et al, ${ }^{5}$ reported that a free radical scavenger had no protective effect on the GNP loaded cells exposed to $3 \mathrm{MeV}$ protons while the mentioned protective effects were reported in the $\mathrm{X}$-ray irradiation. Additionally, they concluded that the GNPgenerated free radicals are a major cause of radiosensitization and then, much less DE effect with clinical proton beams reported compared to X-ray. GNPs were used for brachytherapy by ${ }^{169} \mathrm{Yb}$ radionuclide source and the average DE factor was reported as $45.3 \%$ to $51.0 \%$ in the study. Tsiamas et al, ${ }^{6}$ reported a significant DE factor equal to 6 in low energy GNRT and concluded low energy GNRT possibility for deep-seated tumors while greater beam attenuation because of GNPs presence. Zygmanski et al, ${ }^{7}$ studied the parameters affecting the MC simulation microdosimetric calculation of DE due to GNPs results. They concluded that the nonlinear relation between DE factor for a single and multiple GNPs suggests that the parameters such as the number of adjacent nanoparticles per cell, the GNPs distances, and the cellular target may be important in assessing the biological effectiveness associated with GNP. Additionally, they concluded that for a single GNP the spatial distribution of micro-DE Factor ( $\mathrm{mDEF}$ ) has been found to be nearly isotropic 
with limited magnitude and relatively short range. For a cluster of GNPs both the magnitude and range were found much greater. McMahon et al, ${ }^{8}$ also stated that dose inhomogeneity has a dramatic effect on DEF of GNPs and consequently on cell killing increase. They utilized both MC simulation and experimental cell line irradiation. On the other hand, the studies with the MCNP code have shown the DEF exists only for kilovoltage beams and is negligible for megavoltage radiations. Theoretical and experimental studies have been conducted on the GNPs mechanism of DE. ${ }^{9-14}$ Some researchers have studied GNPs radiosensitization and reported the large local dose enhancement (LDE). ${ }^{15-18}$ Additionally, photon, electron, and proton beam applied to the GNPs radiosensitization study using the $\mathrm{MC}$ simulation as well as different sizes of the GNPs. ${ }^{18,19}$ In the result of different studies it can be found that the GNPs perform better in DE for low photon energy and within some micrometers around the irradiated GNP. ${ }^{20,21}$ For the low energy photon beams the photoelectric effect is the most important for DEF while for high energy megavoltage radiation beams the pair-production. DEF for different sizes of GNP and different irradiation conditions also has been studied. Also, DEF was calculated for other types of radiation. The electrons and positrons (e and $\mathrm{e}^{+}$). were applied for GNPs radiosensitization. Macroscopic DEF be considering as average of dramatic inhomogeneity in DE in close vicinity of the GNPs mainly due to the secondary electrons with short rang. High linear energy transfer (LET) and short-range secondary electrons releasing in photon and GNP photoelectric interaction may be one of the reported inhomogeneities in DE. ${ }^{8,22-26}$ In the current study, we used the MCNPX code of the MC simulation method we quantitatively characterize every single type of interaction. The macroscopic DE due to GNPs was numerically obtained. This approach determines the variation of the effects with energy and GNP size and also numerically results in the weight of each effect in energy deposition. The aim of this study was to characterize GNP caused DE in microscopic and macroscopic scale as well as evaluate of dose inhomogeneity effect on the GNP. We also numerically characterized photons and GNPs physical interactions in terms of their weight and portion in the energy transferring to the GNP loaded media. This part of the study tried to respond which part of the absorbed dose is caused by which physical phenomenon. Finally, the main phenomena affecting the $\mathrm{mDE}$ and MDE were determined and discussed.

\section{Materials and Method}

Macrodosimetric and microdosimetric simulations were conducted to characterize $\mathrm{MDE}$ and $\mathrm{mDE}$ in the recently proposed GNRT method. The weight of each physical interaction between the GNPs and radiation was characterized in the uniformly GNP-filled tumor. A small spherical tumor of $2 \mathrm{~cm}$ diameter immersed in a $30 \times 30 \times 30 \mathrm{~cm}^{3}$ water phantom. In the case of kilovoltage beams, the tumor was positioned at the phantom surface. In the case of megavoltage beams, the tumor was placed at $d_{\max }$. The simulated tumor with $3 \mathrm{mg} / \mathrm{g}$ and 7 $\mathrm{mg} / \mathrm{g}$ GNP concentration was irradiated by megavoltage and kilovoltage photon beams separately. Photon beams with energies of $18 \mathrm{MV},{ }^{60} \mathrm{Co}$ gamma rays, and $75 \mathrm{kVp}$ were used to irradiate the tumor. For the tumor irradiation with megavoltage photon beam, the dose distribution for ${ }^{60} \mathrm{Co}$ source and an $18 \mathrm{MV}$ Varian 2100 Clinac were simulated. The result of the calculations was verified and benchmarked. The dose distribution for linac was benchmarked and verified by comparison the calculation results with measured percent depth dose (PDD) and photon beam profiles (BP) for several field sizes. MDE due to GNPs in the modeled tumor cell was studied using the simulated sources and two mentioned GNP concentrations. The diameter of the spherical GNPs was $50 \mathrm{~nm}$. Two different tumors with different concentrations of GNP were considered. The simulation of tumors' irradiation placed in the water phantom was carried out with the $5 \times 5 \mathrm{~cm}^{2}$ field size. The MDEF and $\mathrm{mDEF}$ were calculated for every type of interaction separately. The ratio of mass-energy absorption coefficient defined as the ratio of absorbed dose in tumor cells with and without GNP was also calculated. For the calculations, two separate input files used with and without GNPs (concentrations of $7 \mathrm{mg}-\mathrm{Au} / \mathrm{g}$ and $3 \mathrm{mg}-\mathrm{Au} / \mathrm{g}$ ). The $10^{10}$ photons (particles) histories were used in the MC simulation to have a statistical error of about 0.01. In all simulations, the initial photon numbers were the same and that is why we omitted the number of photons in Equation 1. The obtained value was the $\mu_{\mathrm{en}} / \rho$ of GNP-filled water.

$\frac{\frac{* F 8}{\frac{M}{\rho}}}{\frac{* F 8}{\frac{M}{\rho}}}$

Eq. 1

To derive the mass-energy transfer coefficient $\left(\frac{\mu_{t r}}{\rho}\right)$, F6 tally was used which scores kerma value instead of $* \mathrm{~F} 8 / \mathrm{gr}$ which scores absorbed dose in MCNP code of MC.

Below equation is applied for $\mu_{\mathrm{tr}} / \rho$ calculation by $\mathrm{MC}$ simulation.

$\frac{\frac{F 6}{\rho}}{\frac{F 6}{\rho}}$

In Equation 2, F6 tally scored kerma in ( $\mathrm{MeV} / \mathrm{g}$ which converted to $\mathrm{J} / \mathrm{Kg}$ ) and absorbing mass inserted in $\mathrm{Kg}$. the same as the Equation 1, the dominator was calculated with GNP and the denominator was calculated without GNP.

In the second part of this study, a single GNP with a size of $50 \mathrm{~nm}$ and in spherical shape was modeled in center of tumor. The mDE influence by GNP was calculated in each $1 \mu \mathrm{m}$ in a lattice filled tumor with $1 \mu \mathrm{m}$ side from center of the single GNP. The calculation was performed to derive dose inhomogeneity around a single GNP. The tumors were positioned at $d_{\max }$ and on the surface in the megavoltage and kilovoltage beams respectively. 
The effect of a single GNP placed in a small volume as inhomogeneity was specified. The DE scored in $1 \mu \mathrm{m}$ steps. On the other hand, in the same configuration, running the program, photoelectric, pair-production, Compton effect, bremsstrahlung X-ray production in tumor and radiation scattering weights also were scored.

For ${ }^{60} \mathrm{Co}$ beam, the estimated dose in the GNP-filled phantom and GNP-free phantom ratio was shown in narrow energy bins in Figure 1. The result was used to investigate the change of the tumor radiological properties caused by GNPs. The primary source particle number required to delivering 1 Gy dose to the isocentre was also calculated. The interactions and phenomenon weights ratio in absence of GNPs to the result in presence of GNPs and the portion of each studied interaction was determined and the results were compared. Our study focused on the numerical characterization of the interactions portion in the energy transfer in addition to the magnitudes of $\mathrm{mDE}$ and MDE. Furthermore, the dose inhomogeneity investigation was the other aim of this paper. DNA strand breaks caused by ionizing radiation can more frequent due to a local dose enhancement (LDE).

The results of the study on DE were conducted by use of MC modeling and the model was benchmarked comparing with the other related works. Dose gradient within first $30 \mu \mathrm{m}$ from the center of the single GNP calculate and dose variation curve was presented for all energies of photons. In the current study micro-scale calculation is conducted for nano-scaled particles.

\section{Results}

The results of interactions portion in dose deposition, to change in tumor radiological properties and MDE in the modeled concentrations were presented in Table 1. As shown in Table 1, the addition of $7 \mathrm{mg}-\mathrm{Au} / \mathrm{g}$ of tumor to the tumor composition led to MDE of 1-15\%. Additionally, decreasing the source energy increases the MDE by a factor of 15 and higher for the lowest beam energy. The effect is explained by the fact that the photo-electric effect becomes the predominant interaction for low kilovoltage energies. Energy deposition per each interaction per source particle was tabulated in Table 2.
As shown in Table 2, energy deposition via photo-electric interaction is $35 \%$ higher for $300 \mathrm{kVp}$, for which the mean energy of the spectrum lies between $75-100 \mathrm{keV}$. Contrary, for the $18 \mathrm{MV}$ the mean energy of the spectrum is between 4.5$6 \mathrm{MeV}$ photon beam irradiation. The Compton effect is the most probably for this energy with some pair production. While the weight of pair-production increases with increases in energy. For the $300 \mathrm{kV}$ photon spectrum, megavoltage ${ }^{60} \mathrm{Co}$ quality, and $18 \mathrm{MV}$ photon spectrum, MDEF obtained were $1.54,1.08$, and 1 respectively. On average, photoelectric weight in MDE was shown $38 \%$ higher for $300 \mathrm{kV}$ photons in comparison to $18 \mathrm{MV}$ photon beam regardless of the concentration of GNPs. The MC simulation showed that the $19 \%$ and $7 \%$ increase in the photo-electric interaction obtained at $300 \mathrm{kV}$ spectrum and $18 \mathrm{MV}$ photon spectrum respectively irradiation in the same condition. The inverse-square attenuation factor, ${ }^{2}$ the photon attenuation by air $^{3}$ and photon beam attention by water may be one of the causes of low contribution of the pair production in the megavoltage photon beam DE in presence of GNPs. With the increase of the photon energy from the ${ }^{60} \mathrm{Co}$ quality to $18 \mathrm{MV}$ spectra, pair-production weight in MDEF decreased 7\% while the photoelectric portion increased by $19 \%$ in MDEF. The probability of the photoelectric effect was two times larger for a higher concentration of GNPs. The increase of pair-production was small. Compton effect did not depend on the conditions analyzed in this study. The atomic and sub-atomic effects were investigated by deriving differences in the energy absorption coefficient $\mu_{\mathrm{en}}$ in the presence and absence of GNPs. Figure 1 shows $\mu_{\mathrm{en}}$ as a function of energy for $7 \mathrm{mg}-\mathrm{Au} / \mathrm{g}$ and $3 \mathrm{mg}$ $\mathrm{Au} / \mathrm{g}$ of tissue concentrations. As can be seen in Figure 2, radiation absorption peaks shifted to the lower energies, and magnitude of the coefficient was increased for low energies. Three main peaks can be seen in the absorbed dose spectrum. The peaks occurred at $40 \mathrm{keV}, 540 \mathrm{keV}$, and $860 \mathrm{keV}$ in the $18 \mathrm{MV}$ linac based irradiation. Other peaks also are seen in the spectra for the water and mixture of the water and GNPs.

Table 1. (50nm) GNPs dose enhancement characterization in different conditions

\begin{tabular}{|c|c|c|c|c|c|c|c|}
\hline \multicolumn{8}{|c|}{$18 \mathrm{MV}$} \\
\hline Field Size $\left[\mathrm{cm}^{2}\right]$ & $\begin{array}{c}\text { Concentration } \\
{[\%]}\end{array}$ & DGNP/D0 & $\begin{array}{c}\text { Photoelectric weight } \\
\text { Ratio }\end{array}$ & $\begin{array}{c}\text { Pair production } \\
\text { weight Ratio }\end{array}$ & $\begin{array}{c}\text { Compton } \\
\text { weight Ratio }\end{array}$ & $\begin{array}{c}\boldsymbol{\mu}_{\text {en }}[\mathrm{GNP}] / \boldsymbol{\mu}_{\mathrm{en}}[\mathbf{0}] \\
{[\text { Maximum }]}\end{array}$ & $\begin{array}{c}\text { DE factor } \\
{[\%]}\end{array}$ \\
\hline \multirow{2}{*}{$5 \times 5$} & $7 \mathrm{mg} / \mathrm{g}$ & 1.01 & 1.14 & 1.08 & 1.00 & 1.66 & 1.01 \\
\hline & $3 \mathrm{mg} / \mathrm{g}$ & 1.01 & 1.12 & 1.08 & 1.00 & 1.57 & 1.00 \\
\hline \multicolumn{8}{|c|}{$6 \mathrm{MV}$} \\
\hline \multirow{2}{*}{$5 \times 5$} & $7 \mathrm{mg} / \mathrm{g}$ & 1.01 & 1.16 & 1.05 & 1.00 & 1.71 & 1.07 \\
\hline & $3 \mathrm{mg} / \mathrm{g}$ & 1.01 & 1.15 & 1.05 & 1.00 & 1.67 & 1.03 \\
\hline \multicolumn{8}{|c|}{${ }^{60} \mathrm{Co}$} \\
\hline \multirow{2}{*}{$5 \times 5$} & $7 \mathrm{mg} / \mathrm{g}$ & 1.02 & 1.21 & 1.00 & 1.00 & 1.87 & 2.01 \\
\hline & $3 \mathrm{mg} / \mathrm{g}$ & 1.02 & 1.21 & 1.00 & 1.00 & 1.84 & 1.06 \\
\hline \multicolumn{8}{|c|}{$300 \mathrm{kV}$} \\
\hline \multirow{2}{*}{$5 \times 5$} & $7 \mathrm{mg} / \mathrm{g}$ & 1.13 & 1.54 & N/A & 1.00 & 2.09 & 13.02 \\
\hline & $3 \mathrm{mg} / \mathrm{g}$ & 1.11 & 1.53 & N/A & 1.00 & 2.00 & 11.03 \\
\hline
\end{tabular}


Table 2a. The phenomena energies calculation in our model including a single GNP $(\mathrm{E}=18 \mathrm{MV})$

\begin{tabular}{|c|c|c|c|c|c|c|}
\hline & Knock-on & Bremsstrahlung & Scattering & Photoelectric & Pair-Production & Compton \\
\hline $\begin{array}{l}\text { Deposited energy per particle } \\
(3 \mathrm{mg} / \mathrm{g} \mathrm{Au}) \text { in } \mathrm{MeV}\end{array}$ & $7.45 \times 10^{-5}$ & $7.37 \times 10^{-5}$ & $8.57 \times 10^{-6}$ & $1.14 \times 10^{-8}$ & $1.45 \times 10^{-4}$ & $9.98 \times 10^{-5}$ \\
\hline $\begin{array}{l}\text { Sum of deposited energy per } \\
\text { particle }(3 \mathrm{mg} / \mathrm{g} \mathrm{Au}) \text { in } \mathrm{MeV}\end{array}$ & \multicolumn{6}{|c|}{$4.02 \times 10^{-4}$} \\
\hline $\begin{array}{l}\text { Deposited energy calculated by tally } \\
\text { per source }(3 \mathrm{mg}-\mathrm{Au} / \mathrm{g}) \text { in } \mathrm{MeV}\end{array}$ & \multicolumn{6}{|c|}{$3.98 \times 10^{-4}$} \\
\hline $\begin{array}{l}\text { Difference between the tally scored } \\
\text { and calculated energy }(3 \mathrm{mg} / \mathrm{g} \mathrm{Au})\end{array}$ & \multicolumn{6}{|c|}{0.99} \\
\hline $\begin{array}{l}\text { DE (in } 5 \mu \mathrm{m}) \text { by the events energy } \\
\text { deposition }(3 \mathrm{mg} / \mathrm{g} \mathrm{Au})\end{array}$ & \multicolumn{6}{|c|}{$21.01 \%$} \\
\hline DE by tallying process $(3 \mathrm{mg} / \mathrm{g} \mathrm{Au})$ & \multicolumn{6}{|c|}{$1.978 \%$} \\
\hline $\begin{array}{l}\text { Difference of the DE calculated by } \\
\text { two methods }(3 \mathrm{mg} / \mathrm{g} \mathrm{Au})\end{array}$ & \multicolumn{6}{|c|}{$5.84 \%$} \\
\hline
\end{tabular}

Table 2b. The phenomena energies calculation in our model including a single GNP $(\mathrm{E}=18 \mathrm{MV})$

\begin{tabular}{|c|c|c|c|c|c|c|}
\hline & Knock-on & Bremsstrahlung & Scattering & Photoelectric & Pair-Production & Compton \\
\hline $\begin{array}{l}\text { Deposited energy per particle } \\
(7 \mathrm{mg} / \mathrm{g} \mathrm{Au}) \text { in } \mathrm{MeV}\end{array}$ & $9.31 \times 10^{-5}$ & $2.82 \times 10^{-4}$ & $9.91 \times 10^{-6}$ & $1.20 \times 10^{-8}$ & $1.98 \times 10^{-4}$ & $2.11 \times 10^{-4}$ \\
\hline $\begin{array}{l}\text { Sum of deposited energy per } \\
\text { particle }(7 \mathrm{mg} / \mathrm{g} \mathrm{Au}) \text { in } \mathrm{MeV}\end{array}$ & \multicolumn{6}{|c|}{$6.93 \times 10^{-4}$} \\
\hline $\begin{array}{l}\text { Deposited energy calculated by tally } \\
\text { per source }(7 \mathrm{mg}-\mathrm{Au} / \mathrm{g}) \text { in } \mathrm{MeV}\end{array}$ & \multicolumn{6}{|c|}{$6.89 \times 10^{-4}$} \\
\hline $\begin{array}{l}\text { Difference between the tally scored } \\
\text { and calculated energy }(7 \mathrm{mg} / \mathrm{g} \mathrm{Au})\end{array}$ & \multicolumn{6}{|c|}{0.55} \\
\hline $\begin{array}{l}\text { DE (in } 5 \mu \mathrm{m}) \text { by the events energy } \\
\text { deposition }(7 \mathrm{mg} / \mathrm{g} \mathrm{Au})\end{array}$ & \multicolumn{6}{|c|}{$31.27 \%$} \\
\hline DE by tallying process $(7 \mathrm{mg} / \mathrm{g} \mathrm{Au})$ & \multicolumn{6}{|c|}{$2.173 \%$} \\
\hline $\begin{array}{l}\text { Difference of the DE calculated by } \\
\text { two methods }(7 \mathrm{mg} / \mathrm{g} \mathrm{Au})\end{array}$ & \multicolumn{6}{|c|}{$5.79 \%$} \\
\hline
\end{tabular}

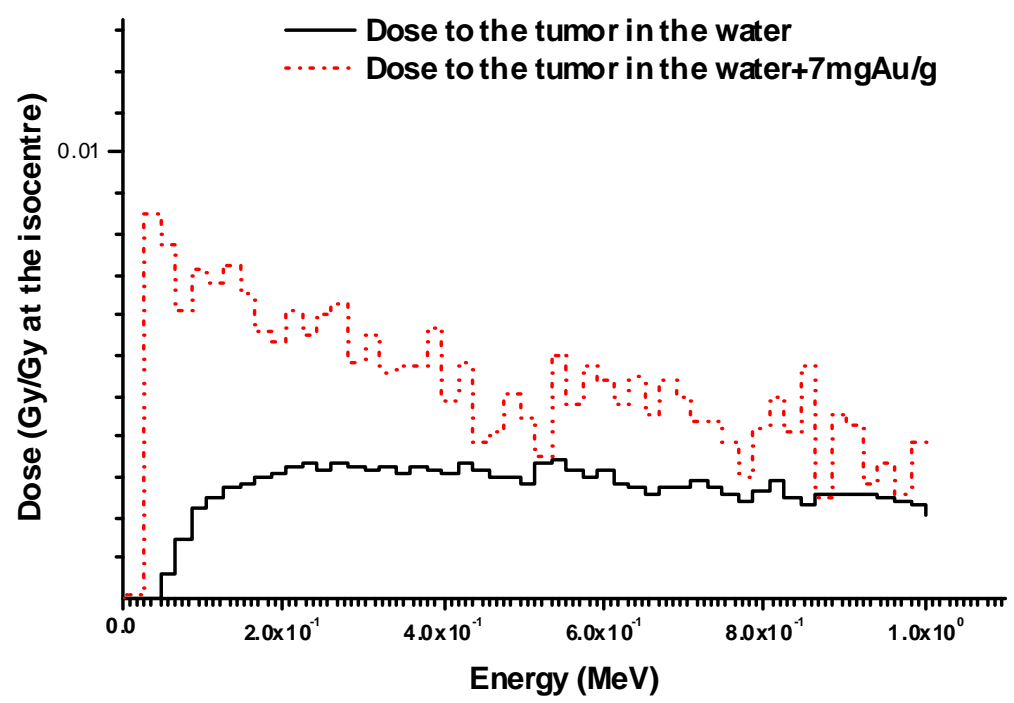

Figure 1. Absorbed dose spectrum in the tumor in the narrow energy bins. 


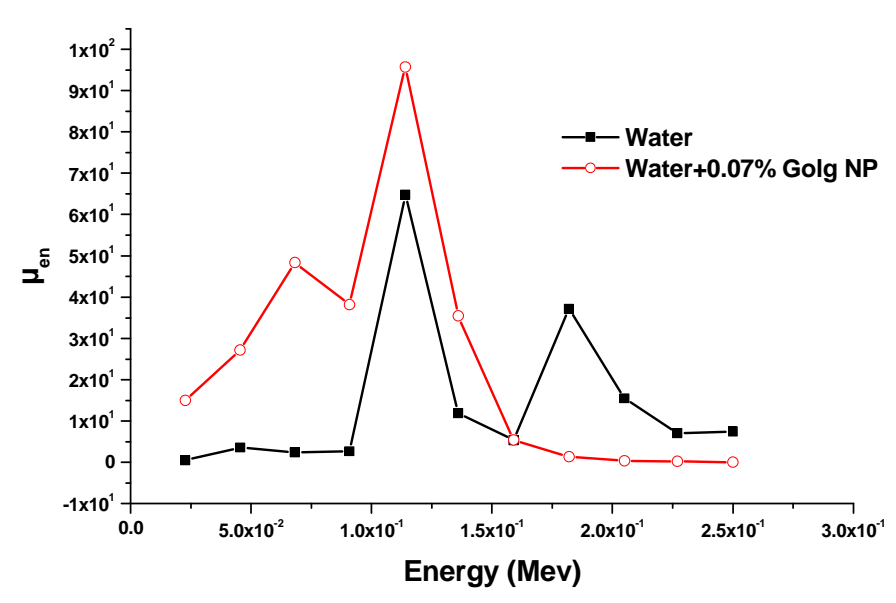

Figure 2a. Radiation Absorption Coefficient changes in presence of $7 \mathrm{mg}$-Au per $\mathrm{gr}$ of tumor.

\section{Discussion}

From the results, it was seen that sensitization of DE is mostly photo-electric dependent. The sensitization of DE is small for the pair-production. Especially for ${ }^{60} \mathrm{C}$ quality as the lower megavoltage energy source irradiation, photo-electric is the predominant source of the increase of MDE. It has a much larger influence on MDE than pair-production. The ratio of $\mu_{e n}$ in the presence of GNPs and the GNPs obtained for free water was seen higher for a high concentration of GNP. The ratio was seen up to 2.09 and 2.00 for the high and low concentrations in the current study respectively. In Figure 2, the absorbed dose in the tumor in the narrow energy bins was shown. The higher dose was in the water included some GNPs while in case of lack of GNPs the dose decreases. Table 2 reveals the dominancy of the photoelectric and low weight of other phenomena. The results revealed (see Table 2) that the absorption of energy in photoelectric and pair-production depends on the characteristic of the GNP-filled tumor. It depended on the GNP concentration what changed the DE.

As seen in Figure 1, for low energies MDE is higher than that of for high energies. A dramatic increase of dose seen in Figure 1 in the lowest energies range is attributed to the photoelectric effect, which is the predominant effect. Macroscopic dosimetry using physical dosimeters such as gel dosimetry as well as dose distribution calculations by MC in a millimeterscaled scoring are not able to explain the increase in observed LDE in the tumor which was reported in most in vivo and cell culture studies. It is because LDE is a microscopic value and scoring in micrometer and smaller scales can show it only. As energy increased, MDE decreased and the spectra of photons in two water complexes with and without GNP approached together. As discussed, MDE decreases while the energy of photons is increasing. One can consider another role of the photoelectric effect in MDE. Because of high MDE in the lower energies, the application of the GNPs as a contrast agent in molecular and cancer imaging is the subject of many studies.

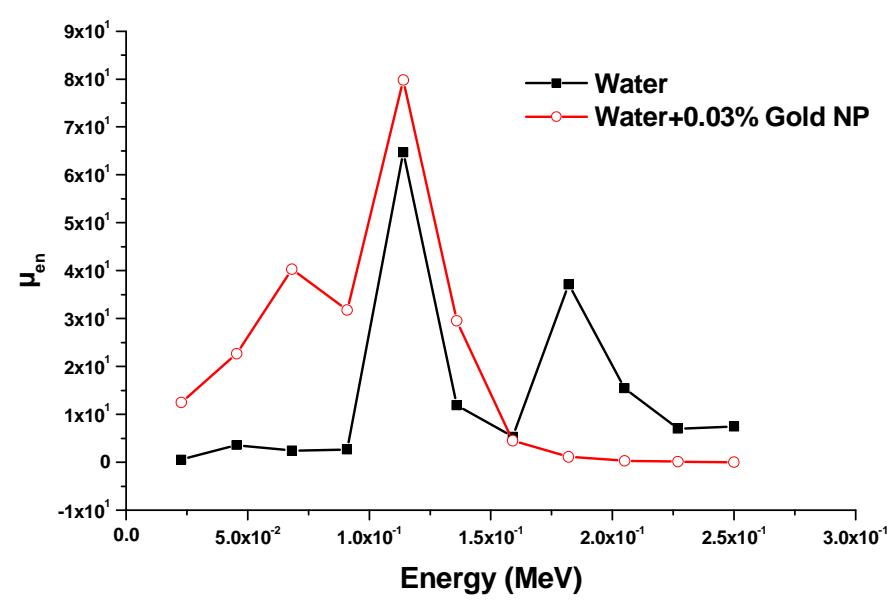

Figure 2b. Radiation Absorption Coefficient changes in presence of $3 \mathrm{mg}$-Au per gr of tumor.

Zhang et al studied DE due to $100 \mathrm{~nm}$ GNPs by GEANT4 toolkit calculation and showed $8 \% \mathrm{DE}$ for $200 \mathrm{KeV}$ irradiation. ${ }^{9}$ Our results for $\mathrm{DE}$ for $300 \mathrm{kVp}$ photon beam and $50 \mathrm{~nm}$ GNPs were $11 \%$ and $13 \%$ for the low and high concentration of GNPs. The difference may be attributed to the characteristics of the beams. They modeled a $200 \mathrm{keV}$ monoenergetic photon beam while in this study we modeled a 300 $\mathrm{kVp}$ bremsstrahlung spectrum which includes many lowerenergy photons, much larger than their beam. Our modeled beam's average energy lies between $75 \mathrm{keV}$ and $100 \mathrm{keV}$. The beam's maximum energy was $300 \mathrm{keV}$ and the number of photons with the energy is very low. Douglass et al, ${ }^{10}$ investigated DE caused by GNPs with the GEANT4 MC calculation using kilovoltage and megavoltage beams in a $3 \mathrm{D}$ randomized cell model. They modeled $6 \mathrm{MV}$ and $80 \mathrm{kVp}$ photon beams. They reported a $1-10 \%$ increasing in the absorbed dose which is in good agreement with our results. Jones et al, ${ }^{11}$ conducted a microscopic DE investigation by EGSnrc code simulation and reported 2 to $20 \mathrm{DE}$ within $5 \mu \mathrm{m}$ out of GNPs and by $5 \%$ only at a distance of $30 \mu \mathrm{m}$. Additionally, they used several low energy radioisotopes beam, $50 \mathrm{kVp}$, and 6MV X-ray photon beams. Comparison of their results with our shows quite good agreement. For a detailed comparison, photon beam spectrum in the energy of $300 \mathrm{kVp}$ was modeled and in the lattice filled tumor cell, DE in $5 \mu \mathrm{m}$ steps was calculated. It was seen that DE varied from $26 \%$ within the first $5 \mu \mathrm{m}$ to $2 \%$ at the lattice cell at $30 \mu \mathrm{m}$ far from the GNP center. Good agreement was obtained in the comparison between our results and Jones et $\mathrm{al}^{11}$ work in the case of microscopic DE investigation. Figure 3 shows the result of the microscopic investigation of DE. According to the results and result of microscopic DE study, it can be seen that dramatic DE taking place in the vicinity of the GNPs. From the results, perhaps it can be deduced that dose inhomogeneity due to the GNPs has the main role in DE in a sub-cellular phenomenon. In the physical phenomena, photo-electric plays 


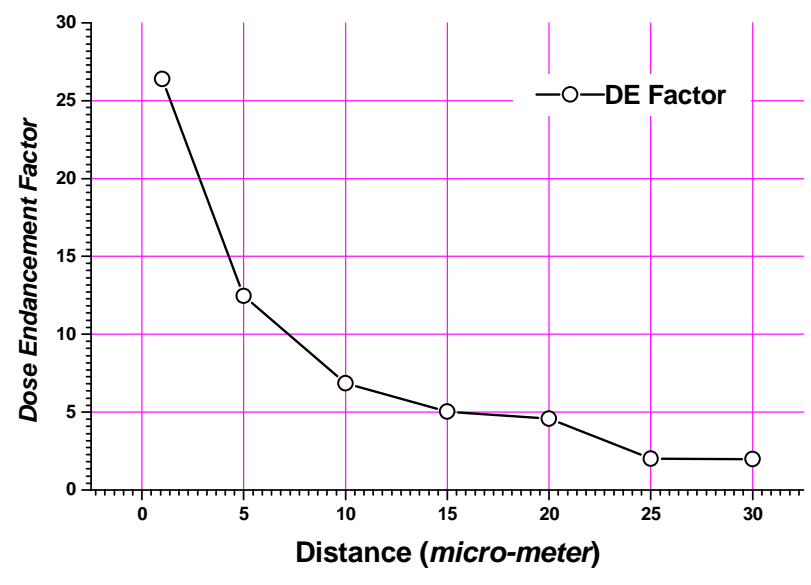

Figure 3. DE as function of distance from the GNP. The manner of $\mathrm{DE}$ is near to an exponential function.

the main role and in the sub-cellular study, dose inhomogeneity is responsible for the biologic effect increases the DE. Our result in the microscopic study is in good agreement with McMahon et $\mathrm{al}^{8}$ results and conclusion. Calculated DE at a distance of $5 \mu \mathrm{m}$ was about 26 times higher than at a distance of $30 \mu \mathrm{m}$ from the GNP. These findings are presented in Figure 3. In Figure 3, it can be seen around 23-27\% DE at
$5 \mu \mathrm{m}$ distance from the single GNP and $2-10 \%$ only at a distance of $30 \mu \mathrm{m}$. High LDE in near distances and high dose inhomogeneity may be the main cause of cell killing using the GNPs in cancer radiation therapy. Dose inhomogeneity due to a single GNP for different energies was shown in Figure 3.

Derived DE and dose inhomogeneity at close vicinity of a single $50 \mathrm{~nm}$ GNP showed differences in the phenomena weight in energy transferring and difference of $\mathrm{mDE}$ and MDE. The gradient of the dose is higher for the high energy, and then the mean DE in a macro-scale may be low for the higher energies. According to Jeynes et $\mathrm{al}^{5}$ in the case of GNPs presence the higher density of free radicals can cause more cell killings.

\section{Conclusion}

From the results, we concluded that in the case of the GNPs the photoelectric effect is the dominant phenomenon causing the dose enhancement. This effect is observed especially for low energy photons. There is a very large dose gradient at close vicinity of the GNPs caused by the short-range electrons what influences very much on the dependence of radiosensitization on distance from GNPs.

\section{References}

1. Mesbahi A. A review on gold nanoparticles radiosensitization effect in radiation therapy of cancer. Rep Pract Oncol Radiother. 2010;15(6):176-180.

2. Qian X, Peng X-H, Ansari DO, et al. In vivo tumor targeting and spectroscopic detection with surface-enhanced Raman nanoparticle tags. Nat Biotechnol. 2008;26(1):83-90.

3. Leung MK, Chow JCL, Chithrani BD, et al. Irradiation of gold nanoparticles by x-rays: Monte Carlo simulation of dose enhancements and the spatial properties of the secondary electrons production. Med Phys. 2011;38(2):624-631.

4. Zaman RT, Diagaradjane P, Wang J, et al. In vivo detection of gold nanoshells in tumors using diffuse optical spectroscopy. IEEE Journal of Selected Topics in Quantum Electronics. 2007;14(6):1715-1720.

5. Jeynes JC, Merchant MJ, Spindler A, et al. Investigation of gold nanoparticle radiosensitization mechanisms using a free radical scavenger and protons of different energies. Phys Med Biol. 2014;59(21):6431-6434.

6. Tsiamas P, Mishra P, Cifter F, et al. Low-Z linac targets for low-MV gold nanoparticle radiation therapy. Med Phys. 2014;41(2):021701. doi: 10.1118/1.4859335

7. Zygmanski P, Liu B, Tsiamas P, et al. Dependence of Monte Carlo microdosimetric computations on the simulation geometry of gold nanoparticles. Phys Med Biol. 2013;58(22):7961-7977.

8. McMahon SJ, Hyland WB, Muir MF, et al. Nanodosimetric effects of gold nanoparticles in megavoltage radiation therapy. Radiother Oncol. 2011;100(3):342-347.

9. Zhang S, Li J, Lykotrafitis G, et al. Size-dependent endocytosis of nanoparticles. Adv Mater. 2009;21(4):419-424.

10. Douglass M, Bezak E, Penfold S. Monte Carlo investigation of the increased radiation deposition due to gold nanoparticles using kilovoltage and megavoltage photons in a 3D randomized cell model. Med Phys. 2013;40(7):071710. doi: 10.1118/1.4808150

11 Jones BL, Krishnan S, Cho SH. Estimation of microscopic dose enhancement factor around gold nanoparticles by Monte Carlo calculations. Med Phys. 2010;37(3):3809-3816.

12. Xiao QF, Zheng XP, Bu WB, Ge et al. A Core/Satellite Multifunctional Nanotheranostic for in Vivo Imaging and Tumor Eradication by Radiation/Photothermal Synergistic Therapy. J Am Chem Soc. 2013;135(35):13041-13048.

13. Ghasemi-Jangjoo A, Ghiasi H. Monte Carlo study on the gold and gadolinium nanoparticles radiosensitizer effect in the prostate 125I seeds radiotherapy. Pol J Med Phys Eng. 2019;25(3):165-169 
14. Wen L, Chen L, Zheng SM, et al. Ultrasmall Biocompatible WO3-x Nanodots for Multi-Modality Imaging and Combined Therapy of Cancers. Adv Mater. 2016;28(25):5072-5079.

15. McKinnon S, Guatelli S, Incerti S, et al. Local dose enhancement of proton therapy by ceramic oxide nanoparticles investigated with Geant4 simulations. Phys Medica. 2016;32(12):1584-1593.

16. Taggart LE, McMahon SJ, Butterworth KT, et al. Protein disulphide isomerase as a target for nanoparticle-mediated sensitisation of cancer cells to radiation. Nanotechnology. 2016;27(21):215101.

17. Jain S, Coulter JA, Hounsell AR, et al. Cell-specific radiosensitization by gold nanoparticles at megavoltage radiation energies. Int $\mathbf{J}$ Radiat Oncol Biol Phys. 2011;79(2):531-539.

18. Butterworth KT, McMahon SJ, Taggart LE, Prise KM. Radiosensitization by gold nanoparticles: effective at megavoltage energies and potential role of oxidative stress. Transl Cancer Res. 2013;2(4):269-279.

19. Du FY, Zhang LR, Zhang L, et al. Engineered gadolinium-doped carbon dots for magnetic resonance imaging-guided radiotherapy of tumors. Biomaterials. 2017;121:109-120.

20. Ghasemi JA, Ghiasi H, Mesbahi A. A Monte Carlo study on the radio-sensitization effect of gold nanoparticles in brachytherapy of prostate by 103Pd seeds. Pol J Med Phys Eng. 2019;25(2):87-93.

21. Xie WZ, Friedland WF, Li WB, et al. Simulation on the molecular radiosensitization effect of gold nanoparticles in cells irradiated by x-rays. Phys Med Biol. 2015;60(16):6195-6212.

22. Mi P, Dewi N, Yanagie H, et al. Hybrid calcium phosphate-polymeric micelles incorporating gadolinium chelates for imaging-guided gadolinium neutron capture tumor therapy. ACS Nano. 2015;9(6):5913-5921.

23. Dewi N, Mi P, Yanagie H, et al. In vivo evaluation of neutron capture therapy effectivity using calcium phosphate-based nanoparticles as Gd-DTPA delivery agent. J Cancer Res Clin Oncol. 2016;142(4):767-775.

24. Le Duc G, Miladi I, Alric C, et al. Toward an image-guided microbeam radiation therapy using gadolinium-based nanoparticles. ACS Nano. 2011;5(12):9566-9574.

25. Bridot J-L, Dayde D, Rivière C, et al. Hybrid gadolinium oxide nanoparticles combining imaging and therapy. J Mater Chem. 2009;19:2328-2335.

26. Seo S-J, Han S-M, Cho J-H, et al. Enhanced production of reactive oxygen species by gadolinium oxide nanoparticles under coreinner-shell excitation by proton or monochromatic X-ray irradiation: implication of the contribution from the interatomic deexcitation-mediated nanoradiator effect to dose enhancement. Radiat Environ Bioph. 2015;54:423-431.

27. Mignot A, Truillet C, Lux F, et al. A Top-Down synthesis route to ultrasmall multifunctional Gd-Based silica nanoparticles for theranostic applications. Chem - Eur J. 2013;19:6122-6136. 